\title{
Hematopoiesis Induction
}

National Cancer Institute

\section{Source}

National Cancer Institute. Hematopoiesis Induction. NCI Thesaurus. Code C40739.

Hematopoiesis Induction involves initiation of a process of blood formation; more specifically formation of blood cells that are all derived from hematopoietic stem cells. 